\title{
Chitosan - A Natural Sorbent for Copper Ions
}

\author{
Simona Schwarz' ${ }^{1}$ Mandy Mende1, Dana Schwarz ${ }^{2}$ \\ ${ }^{1}$ Leibniz-Institut für Polymerforschung Dresden e.V., Dept. of Polyelectrolytes and Dispersion \\ Hohe Straße 6, 01069 Dresden, Germany \\ simsch@ipfdd.de; mende@ipfdd.de \\ ${ }^{2}$ Charles University in Prague, Faculty of Science, Department of Organic Chemistry \\ Hlavova 2030/8, 12843 Prague 2, Czech Republic \\ schwarzda@natur.cuni.cz
}

\begin{abstract}
As a result of industrial activities and technological changes, a high and continuously increasing amount of heavy metals and heavy metal containing effluents are released into the environment by different industrial nations. These metals cannot be degraded. Furthermore, because of their toxicity, they are highly detrimental to the environment and human health. Heavy metals accumulate in the food chain and become permanent pollutants in the environment. In the human body they accumulate in different organs causing serious damage.

To overcome this problem, the sorption behaviour of heavy metal ions, in particular copper ions was investigated by apply chitosan flakes, powder, and beads as a natural adsorbent. Metal removal was studied using adsorbance measurements, SEM-EDX, and size measurements. The sorption capacity of chitosan was determined at different concentration and times. The received sorption capacities for copper ions were very promising, with a maximum value of $150 \mathrm{mg} / \mathrm{g}$ on chitosan powder.
\end{abstract}

Keywords: Chitosan, Removal, Heavy metal ion, Sorption, Waste water treatment.

(C) Copyright 2016 Authors - This is an Open Access article published under the Creative Commons Attribution License terms (http://creativecommons.org/licenses/by/3.0). Unrestricted use, distribution, and reproduction in any medium are permitted, provided the original work is properly cited.

\section{Introduction}

Waste water treatment, sludge dewatering, pulp and paper production are typical examples for solidliquid separation through coagulation and flocculation. The overwhelming majority of these processes uses polyelectrolytes to regulate the stability and flocculation properties of the disperse systems. This resulted in a great variety of synthetic and natural flocculants like chitosan and starch as natural products which are now commercially available to meet the specific demands of industrial fields, where an efficient solid-liquid separation is required [1-7]. The removal of inorganic components/particles has been intensively investigated during the last years. Hence, it is much more difficult to remove soluble components like dye $[8,9]$, surfactants, or metal ions. This work will focus on the separation of heavy metal ions especially copper ions with chitosan as a natural polymer.

Heavy metal processing industry has always been a major of concern which affect surface water, drinking waters, ground waters, and rivers contamination. With the agreement to comply limiting values (according to the precautionary principle) [10] as they can be found in the European drinking water directive, the nondamaging of human health at lifelong consumption will be ensured. Actual limiting value of the German drinking water directive of copper ions is $2 \mathrm{mg} / \mathrm{L}$ [11].

Besides the endangerment for the environment and human health, heavy metal containing effluents are a source of potentially regenerative materials. The separation and recuperation of heavy metals from the material flow is ecologically and economically required. Thus, the implication is to design efficient and effective strategies to recycle and recover heavy metal ions from industrial effluents $[12,13]$. The intention of this study is the development of a process, which can be used to separate heavy metals in a selective manner from the effluents, especially at low concentrations. The separation is supposed to be accomplished with the help of polyelectrolytes. Since several decades, researches carried out a method of separating heavy metals from effluents by using polyelectrolytes. In 1996, it was shown within an ultra filtration experiment that polyelectrolytes are promising substances to remove 
traces of heavy metals from industrial effluents [14]. Furthermore, it was proved that remaining amount of heavy metal in decontaminated water could significantly be reduced by application of polymeric flocculants, in comparison to inorganic flocculants [15].

Chitosan is a natural polymer and prepared by the deacetylation of chitin. The degree of deacetylation reclines between 50 and $100 \%$. The good sorption properties of chitosan on heavy metal ions has long been known and is mainly attributed to the presence of the so formed secondary amino groups which occur both charged or uncharged depending on the $\mathrm{pH}$ of the solution. So far, various articles have been published focussing on the removal of watersoluble impurities especially heavy metal ions using polyelectrolytes like poly(acrylic acid) and poly(ethylene imine), or chitosan as a soluble flocculation or chelating agent [15]. In this work, we focused on the removal of copper ions by using defined chitosan flakes, powder, and beads as efficient adsorber material.

\section{Experimental}

Chitosan was purchased from BioLog $\mathrm{GmbH}$. The degree of deacetylation (DA) reclines between 85 and $90 \%$ for the investigated samples displayed in Table 1:

Table 1. Properties of the investigated chitosan samples, DA - degree of deacetylation.

\begin{tabular}{|l|l|l|l|}
\hline Sample Name & DA & Molar Mass & Ash Content \\
\hline Ch90/200/A1 & $90 \%$ & $200,000 \mathrm{~g} / \mathrm{mol}$ & $<1 \%$ \\
\hline Ch85/400/A2 & $85 \%$ & $400,000 \mathrm{~g} / \mathrm{mol}$ & $<2 \%$ \\
\hline
\end{tabular}

The investigated Chitosan materials differed in their degree of deacetylation, particle size, and morphology (i.e. flakes, powder, or beads). With laser diffraction we determined a particle size distribution of the powder with a D 50 value of $100 \mu \mathrm{m}$. The flakes have a wide particle size distribution with a $D 50$ value of $635 \mu \mathrm{m}$. But few of the flakes have a size in the $\mathrm{mm}$ range. The beads had a diameter of about $3 \mathrm{~mm}$ in the swollen state. The beads are on basis of alginate coated with chitosan.

The sorption capacities were determined in dependence on the initial concentration of copper ions in solution, as well as on the time of sorption (contact time between adsorbent and adsorbate). Copper sulfate pentahydrate was utilized for all experiments. The sorption investigations were carried out as batch experiments. Sorption capacities were calculated by adsorbance measurements. For every experiment, the concentration of copper ions was measured before and after the sorption procedure at a defined time.

\section{Results and Discussion}

Contact time is a very important parameter for sorption experiments, the sorption capacity calculated later on at a certain time, and for a useful application. Figure 1 shows the increasing amount of copper ions adsorbed on chitosan as a function of time. The maximum sorption uptake has been reached after $24 \mathrm{~h}$. Therefore, for calculating the sorption capacities all batch experiments were carried out after 24 hours sorption when equilibrium was reached. Almost $100 \%$ of the copper ions were removed from water after 24 hours for an initial copper concentration of $180 \mathrm{mg} / \mathrm{L}$. Furthermore, after 1 hour sorption time $60 \%$ of the copper ions were adsorbed in chitosan already.

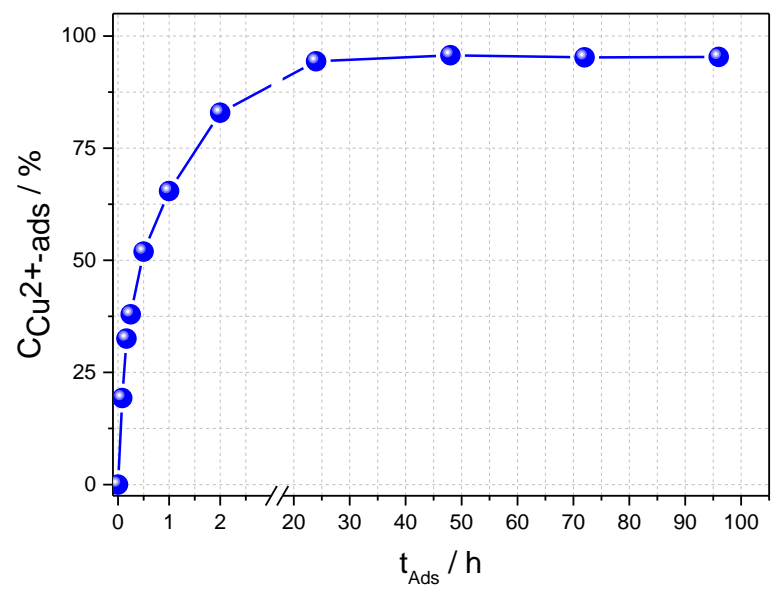

Figure 1. Adsorbed copper ions on chitosan flakes Ch90/200/A1 in dependence on time with an initial copper concentration ( $\mathrm{C}_{\mathrm{Cu} 2+}$ ) of $180 \mathrm{mg} / \mathrm{L}$.

Chitosan is a white material which changes its colour during the sorption of heavy metal ions in aqueous solution towards the colour of the adsorbed metal salt (see Figure 2). The colour intensity depends on the initial concentration of the heavy metal salt as well as on the sorption time. (Copper sulfate is a grey white solid which appears in a beautiful blue colour as shown in Figure 2 in its hydrated form.) The colour change of the material gives evidence of the sorption of copper ions. Furthermore, the adsorbents were characterized be SEM-EDX measurements before and after sorption process (here not shown). The SEM-EDX measurements indicated an sorption of copper ions as well as sulfate ions. 


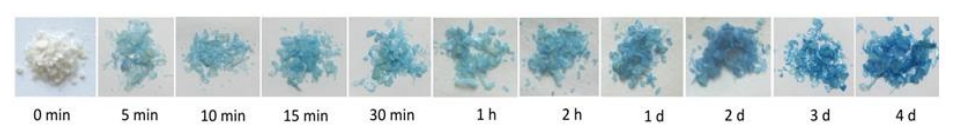

Figure 2. Images of chitosan flakes Ch90/200/A1 in dependence of the sorption time and as a result the increasing colour intensity of chitosan due to the increasing sorption of copper sulfate.

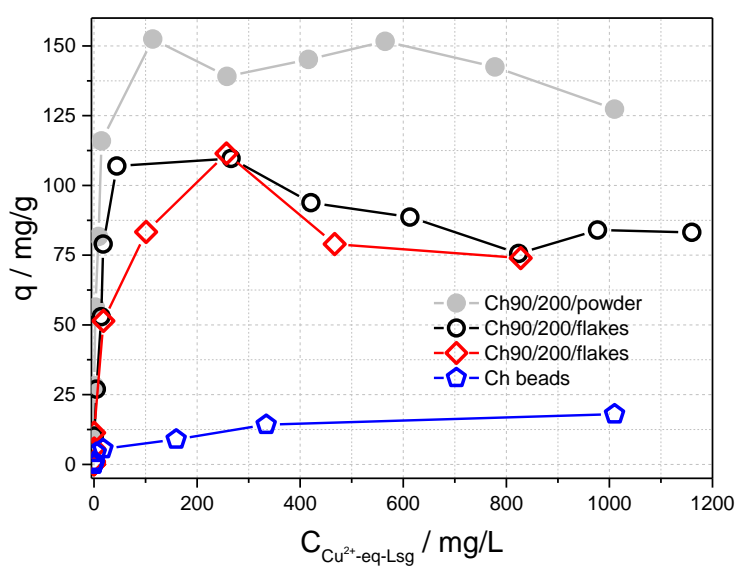

Figure 3. Sorption capacity of different types of chitosan materials in dependence of the initial copper ion concentration, sorption time of $24 \mathrm{~h}$.

In Figure 3 the sorption capacity of the different types of chitosan in dependence of the initial $\mathrm{Cu}$ (II) concentration is shown. The sorption capacity is the difference between the initial concentration of the metal ion and the metal ion concentration after sorption multiplied by the volume used, and divided by the mass of the adsorbent. The $\mathrm{pH}$ of the solutions was not adjusted. The sorption capacities differ significantly from each other in the range powder $>$ flakes $>$ beads. In general, three different sorption capacities could be obtained depending on the morphology of the material. The highest sorption capacity with a maximum value of $150 \mathrm{mg} / \mathrm{g}$ was achieved with the chitosan powder. As the powder had the lowest particle size of all the examined materials, the surface area will be the highest. Hence, the higher the surface area, the higher will be the theoretical sorption capacity. Therefore, the observed values in Figure 3 show a strong dependence on the surface area, thus with the type of chitosan material used. The sorption capacities of the chitosan flakes with 85 and $90 \%$ degree of deacetylation do not differ significantly. The reason could be the small difference in the degree of deacetylation. Hence, the sorption capacity does also depend on the accessibility of the available amino groups. Furthermore, the analised chitosan beads are coated alginate beads with a small layer of chitosan on top of it. Therefore, the beads are difficult for comparison with the other three chitosan materials due to the possible different chemical moieties on the surface, as the amino groups might stick to the alginate surface. This could be another reason for the low sorption capacities on the beads. Investigation on studying the dependence of DA and molar mass for the sorption properties are in progress.

The achieved sorption capacities for copper sorption on chitosan as a natural sorbent are very high in comparison to other adsorbents, independent on the morphology of chitosan. Activated carbon functionalized with secondary amino groups exhibited an sorption capacity of $140 \mathrm{mg} / \mathrm{g}$ for copper ions [16]. Other non natural polymers (e.g. resins and carbamates) possessed sorption capacities between 80 and $70 \mathrm{mg} / \mathrm{g}[17,18,19]$. Much higher sorption capacity were found with ion exchange resin. The maximum sorption capacity of $\mathrm{Cu}$ ions on a special resin was estimated to $324 \mathrm{mg} / \mathrm{g}$ [20]. The sorption capacity on a new type of sorbents on basis of $\mathrm{CaCO}_{3}$ crystals is up to $1041.5 \mathrm{mg} \mathrm{Cu}(\mathrm{II}) / \mathrm{g}$ [21].

Hence, one should note that the sorption capacities of different types of materials were compared without any additional information to it. In this publication the achieved sorption capacities of one natural material with different morphologies was examined and compared. The morphology is one of a number of parameters that are dependent for the sorption capacities.

In further investigations of our work the sorption of other heavy metal ions were described [22-24].

\section{Conclusion}

In principle chitosan is a suitable adsorbent for copper ions in aqueous solution. The highest sorption capacity maximum value of $150 \mathrm{mg} / \mathrm{g}$ was achieved for chitosan powder because of the high accessible surface for copper ions. Chitosan beads have much lower sorption capacities than the chitosan flakes and powder probably due to the small amount of chitosan that was coated on the surface of the alginate beads.

\section{Acknowledgement}

This work was supported by the Central Innovation Programme (ZIM) of the Federal Ministry of Economy and Energy (BMWi) (KF 2022812RH1). The authors thank Heppe Biolog GmbH from Germany for 
the support of the materials and discussion and cooperativeness.

\section{References}

[1] S. Genest, G. Petzold, and S. Schwarz, " Removal of micro-stickies from model wastewaters of the paper industry by amphiphilic starch derivatives," Colloids and Surfaces A: Physicochemical and Engineering Aspects, vol. 484, pp. 231-241, 2015.

[2] S. Bratskaya, S. Genest, K. Petzold-Welcke, T. Heinze, and S. Schwarz, "Flocculation Efficiency of Novel Amphiphilic Starch Derivatives: A Comparative Study," Macromolecular Materials and Engineering, vol. 299, pp. 722-728, 2014.

[3] S. Schwarz and G. Petzold, "Polyelectrolyte Complexes in Flocculation Applications," Advances in Polymer Science, vol. 256, pp. 25-65, 2014.

[4] R. Rojas, S. Schwarz, G. Heinrich, G. Petzold, S. Schütze, and J. Bohrisch, "Flocculation efficiency of modified water soluble chitosan versus commonly used commercial polyelectrolytes," Carbohydrates Polymers, vol. 81, pp. 317-322, 2010.

[5] S. Bratskaya, S. Schwarz, G. Petzold, T. Liebert, and T. Heinze, "Cationic Starches of High Degree of Functionalization: 12. Modification of Cellulose Fibers toward High Filler Technology in Papermaking," Industrial \& Engineering Chemistry Research, vol. 45, pp. 7374-7379, 2006.

[6] S. Schwarz and G. Petzold, "Polyelectrolyte Interactions with Inorganic Particles," in Encyclopedia of Surface and Colloid Science, Third Edition, vol. 6, CRC Press, 2006, pp. 4735-4754.

[7] S. Bratskaya, V. Avramenko, S. Schwarz, and I. Philippova, "Enhanced flocculation of oil-in-water emulsions by hydrophobically modified chitosan derivatives," Colloids and Surfaces A: Physicochemical and Engineering Aspects, vol. 275, pp. 168-176, 2006.

[8] G. Petzold, S. Schwarz, M. Mende, and W. Jaeger, "Dye flocculation using polyampholytes and polyelectrolyte-surfactant nanoparticles," Journal of Applied Polymer Science, vol. 104, pp. 13421349, 2007.

[9] G. Petzold and S. Schwarz, "Dye removal from solutions and sludges by using polyelectrolytes and polyelectrolyte-surfactant complexes,"
Separation and Purification Technology, vol. 51, pp. 318-324, 2006.

[10] Deutscher Bundestag, "Bundesrat, Verordnung zur Novellierung der Trinkwasserverordnung," $2000 . \quad$ [Online]. Available: http://dipbt.bundestag.de/doc/brd/2000/D721+ 00.pdf.

[11] World Health Organization, Guidelines for drinking-water quality. World Health Organization, Geneva, 2011.

[12] BGBl1, "Verordnung zur Novellierung der Trinkwasserverordnung (TrinkwV).," Bundesanzeiger Verlag. Anlage 2 (zu $§ 6$ Abs. 2 Teil I und II TrinkwV + Novellierung Nov. 2011), vol. 24 .zu Bonn, p. 959 ff., 2001.

[13] B. Rivas, E. Pereira, M. Palencia, and J. Sánchez, "Water-soluble functional polymers in conjunction with membranes to remove pollutant ions from aqueous solutions," Progress in Polymer Science, vol. 36, no. 2, pp. 294-322, 2011.

[14] R. S. Juang and M. N. Chen, " Retention of copper(II)-EDTA chelates from dilute aqueous solutions by a polyelectrolyte-enhanced ultrafiltration process," Journal of Membrane Science, vol. 119, no. 1, pp. 25-37, 1996.

[15] S. Bratskayaa, A. Pestovb, Y. Yatlukb, and V. Avramenkoa, "Heavy metals removal by flocculation/precipitation using N-(2carboxyethyl)chitosans," Colloids and Surfaces A: Physicochemical and Engineering Aspects, vol. 339, no. 1-3 , pp. 140-144, 2009.

[16] M. Mahaninia, P. Rahimina, and T. Kaghazchi, "Modified activated carbons with amino groups and their copper adsorption properties in aqueous solution," Chinese Journal of Chemical Engineering, vol. 23, p. 50, 2015.

[17] A. Atia, A. Donia, S. Abou-El-Enein, and A. Yousif, "Studies on uptake behaviour of copper(II) and lead(II) by amine chelating resins with different textural properties," Separation and Purification Technology, vol. 33, no. 3, p. 295, 2003.

[18] Y. Yang, Z. Wei, C. Wang, and Z. Tong, "Ligninbased Pickering HIPEs for macroporous foams and their enhanced adsorption of copper(II) ions," Chemical Communications, vol. 49, pp. 7144-7146, 2013.

[19] X. Jing, F. Liu, X. Yang, P. Ling, L. Li, C. Long, and A. $\mathrm{Li}$, "Adsorption performances and mechanisms of the newly synthesized N,N'-di (carboxymethyl) dithiocarbamate chelating resin toward divalent 
heavy metal ions from aqueous media," Journal of Hazardous Materials, vol. 167, p. 589, 2009.

[20] C. Xiong and C. Yao, "Adsorption Behavior of $\mathrm{Cu}(\mathrm{II})$ in Aqueous Solutions," Iran. J. Chem. Chem. Eng., vol. 32, no. 2, p. 57, 2013.

[21] M. Mihai, I. Bunia, F. Doroftei, C. Varganici, and, B. Simionescu, "Highly Efficient Copper(II) Ion Sorbents Obtained by Calcium Carbonate Mineralization on Functionalized Cross-Linked Copolymers," Chemistry A European Journal, vol. 21, no. 13, p. 5220-5230, 2015.

[22] S. Schwarz, C. Steinbach, D. Schwarz, M. Mende, and R. Boldt, "Chitosan - the Application of a Natural Polymer against Iron Hydroxide Deposition," American Journal of Analytical Chemistry, vol. 7, pp. 623-632, 2016.

[23] M. Mende, D. Schwarz, C. Steinbach, R. Boldt, and S. Schwarz, "Simultaneous adsorption of heavy metal ions and anions from aqueous solutions on chitosan-Investigated by spectrophotometry and SEM-EDX analysis," Colloids and Surfaces A: Physicochemical and Engineering Aspects, 2016.

[24] M. Mende, D. Schwarz, C. Steinbach, R. Boldt, and S. Schwarz, "The Influence of Salt Anions on Heavy Metal Ion Adsorption on the Example of Nickel," Journal of Materials Chemistry. 